\title{
Sense and nonsense about the Fenn effect
}

\author{
JACK A. RALL \\ Department of Physiology, Ohio State University, Columbus, Ohio 43210
}

RALL, JACK A. Sense and nonsense about the Fenn effect. Am. J. Physiol. 242 (Heart Circ. Physiol. 11): H1-H6, 1982.-One of the most influential papers in muscle physiology was published by W. O. Fenn (J. Physiol. London 58: 175-203) in 1923. Fenn determined the quantitative relationship between muscle energy liberation and work performance. Despite the importance of this work, the implications of Fenn's observations are sometimes misunderstood. In this review article, Fenn's experiments are reexamined and the Fenn effect delineated in light of the viscoelastic model of muscle contraction prevalent in the 1920's. The generality of Fenn's results and conclusions are considered in view of more recent results from skeletal and cardiac muscle. Factors responsible for the considerable deviation from Fenn's original results are discussed. Much of the confusion surrounding the generality of Fenn's observations seems to be attributable to the problem of determining an energetic base line for comparing isotonic and isometric contractions. Mommaerts (Physiol. Rev. 49: 427-508, 1969) has suggested the use of an equivalent force base line, which appears to be a useful and unifying concept.

skeletal and cardiac muscle; energetics; mechanics; isotonic and isometric contractions

IN 1922 Wallace O. Fenn went to England to work in A. V. Hill's laboratory on a problem in muscle energetics. Hill suggested that Fenn redetermine the maximum efficiency of work production in skeletal muscle with the improved myothermic techniques then available. These experiments (4) constitute "one of the most notable papers in muscle physiology" (16). Ironically, because of an error in energy calibration (18), Fenn's (4) results concerning efficiency of contraction are not considered useful today, and the efficiency aspect as such is no longer the main point. Despite the significance of Fenn's observations, it has been pointed out that these results often are misunderstood and misquoted (8). Thus several questions ought to be addressed. What did Fenn observe? Why are his results held in high esteem? How universal are these observations and conclusions? Of what significance are these experiments today?

\section{THE FENN EFFECT}

Fenn $(4,5)$ devised experiments to determine the relationship between energy (heat plus work) liberated during isotonic muscle contraction and work performance. These experiments were conducted on frog sartorius muscle, which, as is now known, is the most suitable of preparations. It is an interesting aside that these experiments were conducted in the basement of Hill's house where disturbances of the sensitive myothermic equipment could be minimized and where "room temperature" was often $6-7^{\circ} \mathrm{C}$ (4). Fenn studied afterloaded isotonic contractions. In this type of contraction initial or rest length is first fixed and then the muscle shortens against various afterloads (a load which the muscle does not support while at rest but is subjected to as it shortens during contraction). Typical results are represented in Fig. $1 A$ in which energy liberation and work production in afterloaded isotonic twitches are plotted as a function of afterload at $0^{\circ} \mathrm{C} .{ }^{1}$ Clearly energy liberation is greater as work production becomes greater. In fact energy liberation in excess of that produced in the isometric contraction appears to be proportional to work done. This result is shown more clearly in Fig. $1 B$ where data from different experiments (employing twitches or short tetanic contractions) have been plotted as energy in excess of the maximum isometric value vs. work done. There is a strong tendency for greater excess energy to be liberated as work production increases. Also excess energy liberation is greater than work production. (Dashed line of Fig. $1 B$ represents the case where excess energy equals work done.) From these experiments Fenn $(4,5)$ concluded that 1) "whenever a muscle shortens upon stim-

\footnotetext{
'Heat data has been recalculated from Fenn (4) by multiplying by 0.65 to correct for a likely error in absolute energy calibration (18).
} 

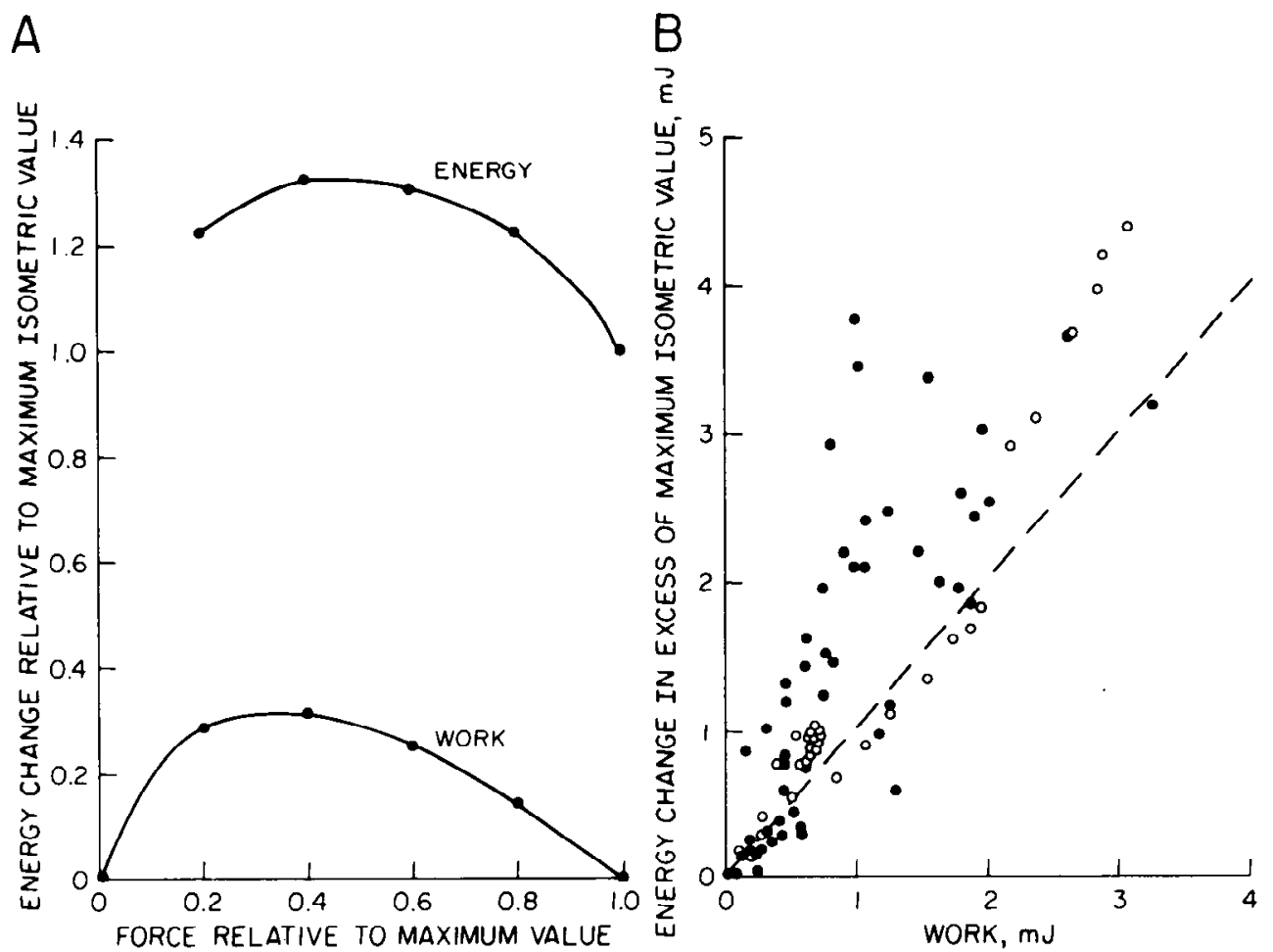

FIG. 1. Energy liberation as a function of fractional load $(A)$ and work $(B)$ in afterloaded isotonic contractions of frog skeletal muscle. $A$ : total energy liberated relative to maximum isometric value in twitches. $B$ : energy liberated in excess of maximum isometric value in twitches and brief tetanic contractions. In $B$, denotes data from afterloaded isotonic contractions where muscles relaxed under the influence of the afterload; $O$ denotes data from afterloaded isotonic contractions where the afterload was varied during contraction so that the muscle relaxed under a small tension. Data from Fenn (4). Heat data recalculated from Fenn (4) by multiplying by 0.65 to correct for a likely error in absoluble energy calibration (18).

ulation and does work in lifting a weight, an extra amount of energy is mobilized which does not appear in an isometric contraction." 2) Further, "the excess energy due to shortening in contraction is very nearly equal to the work done...." These conclusions constitute what has become known as the Fenn effect, i.e., energy (E) liberated during a working contraction approximately equals isometric (I) energy liberation plus work (W) done or E $\cong \mathrm{I}+\mathrm{W}$. The conclusion that the excess energy produced in a shortening contraction is "very nearly equal" to the work done does not fit well with data of Fig. $1 B$ (and even less well with the uncorrected data). But Fenn argued that there was a tendency to overestimate energy liberation for work production when the muscle relaxed under the influence of the afterload. Indeed experiments in which muscles didn't relax under a load (o of Fig. $1 B$ ) produced results closest to the unity slope (dashed line). Nevertheless this point was not firmly established by Fenn's experiments.

To appreciate the significance of Fenn's results it is necessary to understand the prevailing view of muscle contraction in the 1920's. The viscoelastic (or new elastic body) theory of muscle contraction could be traced back to the 1840 's (30). The view was held that, after a stimulus, muscle acted like a stretched spring released in a viscous medium. The stimulated muscle then would liberate, in an all-or-none fashion, an amount of energy that varied with initial length and which could appear as either heat or work. The amount of potential energy that could be converted into work depended on the skill of the experimenter in arranging levers, and thus work should bear no relation to total energy liberated (4). This theory predicts that the amount of energy liberated in an isotonic contraction would be independent of work or load and equivalent to energy liberated in an isometric contraction. Fenn's results clearly were inconsistent with this theory. Hill (17) states that Fenn's conclusions "were obviously the death warrant of the visco-elastic theory." It should be noted that Fenn's repudiation of the viscoelastic theory would only be valid if all of the potential energy set free with stimulation appeared as heat and work. If part of this potential energy reverted to chemical energy at the end of an isometric contraction, then the isometric contraction would liberate less energy than the isotonic contraction, but the viscoelastic theory would still be valid $(25,39)$. Such a reconversion does not occur (3).

Fenn's main conclusion has been generalized (24): “...there is some internal 'feedback' in active muscles whereby their total energy liberation is regulated by the mechanical conditions during the contraction process." This conclusion has remained important because of an historical interest in repudiating a long prevailing model of muscle contraction and a contemporary significance in demonstrating a phenomenon that must be explained in molecular terms by any credible model of muscle contraction. It is an interesting historical note that Fenn's results (4) confirmed data and conclusions of Heidenhain and Fick that were reached decades earlier. But the earlier experiments did not possess the technical clarity of Fenn's experiments.

\section{GENERALITY OF FENN'S RESULTS AND CONCLUSIONS}

In general, results from experiments measuring energy cost during afterloaded isotonic contractions are more varied than Fenn's conclusions would suggest. Figure $2 \mathrm{~A}$ shows examples of some of this variability. Energy or chemical change relative to the maximum isometric value is plotted against force relative to the maximum value as in Fig. $1 A$. These results were collated because 1 ) all were from sartorius muscle, 2) different techniques were 


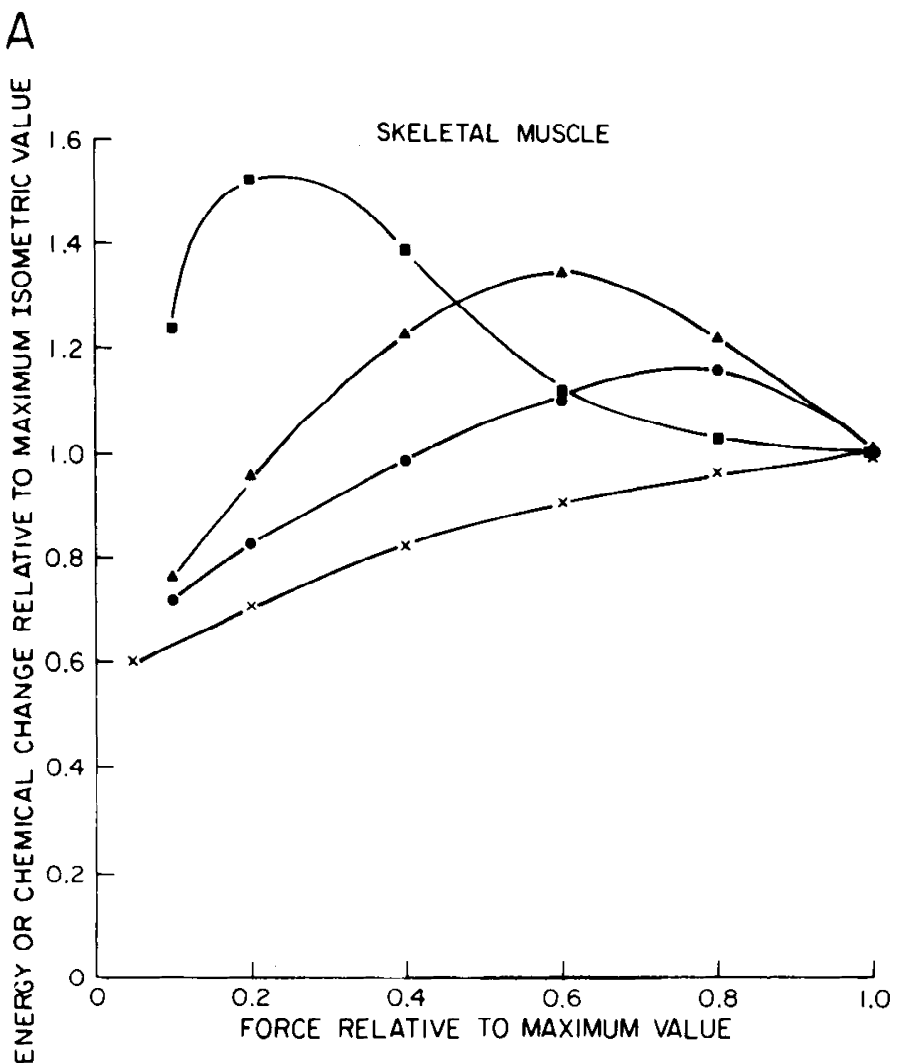

FIG. 2. Fnergy cost as a function of load in afterloaded isotonic contractions of skeletal $(A)$ and cardiac $(B)$ muscle. Data plotted as multiples of maximum isometric values. Techniques and sources: $\mathbf{n}$, high-energy phosphate metabolism, $A(1), B(31) ; \Delta$, mitochondrial

employed, and 3) extremes of these data form an envelope in which other data from skeletal muscle can be included. The curve (a) that most closely resembles Fenn's data was derived from measurements of phosphocreatine hydrolysis in repeated twitches at $0^{\circ} \mathrm{C}(1)$. Also energy liberation was measured in parallel experiments, and similar results were obtained (not shown in Fig. $2 A$ ). Thus these experiments confirmed Fenn's results and further showed that the extra energy liberation in excess of the isometric value can be accounted for by highenergy phosphate metabolism. Nonetheless, one does not always see what Fenn observed. At the other extreme of Fig. $2 A$, data $(\mathrm{x})$ are shown from experiments in which energy liberation in twitches of frog muscle was measured at $20^{\circ} \mathrm{C} \mathrm{(10).} \mathrm{These} \mathrm{results} \mathrm{can} \mathrm{be} \mathrm{compared} \mathrm{to} \mathrm{those} \mathrm{of}$ Fenn because they were obtained from frog sartorius muscle by myothermic techniques. Other data from the same study (10) where muscles were studied during brief tentani at lower temperatures yield results when plotted that are similar to the intermediate examples of Fig. $2 A$. Data shown as solid triangles (22) were obtained by monitoring recovery metabolism noninvasively (by transient diminution of fluorescence of mitochondrial $\mathrm{NADH}$ ) in short tetani of isolated bullfrog muscle at $16^{\circ} \mathrm{C}$. When the same technique was employed in studies of twitches in toad muscle, results closely resembled the energy production curve $(\times)$ of Fig. $2 A(23)$. The final example $(\bullet)$ is derived from oxygen consumption data from repeated twitches in frog muscle at $11-13^{\circ} \mathrm{C}(7)$. Data from other experiments on skeletal muscles that fit

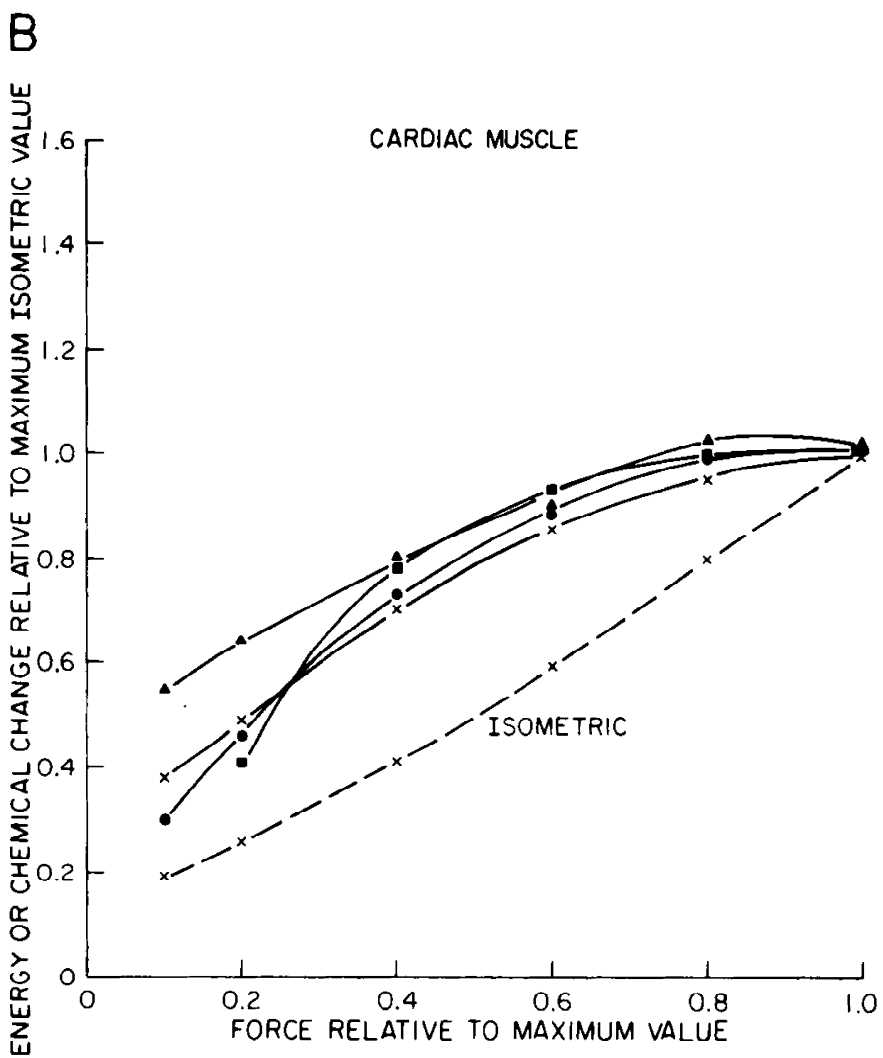

NADH fluorescence, $A(22), B(8)$; $\bullet$, oxygen consumption, $A$ (7), $B(2)$; $\times$, energy utilization, $A(10), B(11)$. Dashed line in $B$ derived from isometric contractions at various preshortened muscle lengths.

into the framework of Fig. $2 A$ include results from twitches in avian tonic and phasic contracting muscle at $21^{\circ} \mathrm{C}$ (34) and tetani in mammalian fast (37) and slow (12) contracting muscle at $27^{\circ} \mathrm{C}$. The emerging picture is that there is a family of curves depicting the relation of energy cost to relative force generation during contraction and that in general $\mathrm{E} \neq \mathrm{I}+\mathrm{W}$, nor is $\mathrm{E}$ constant.

Experimental work on cardiac muscle gives consistent results $(2,8,11,31,38$; Fig. $2 B)$. As in Fig. $2 A$, energy or chemical change relative to the maximum isometric value is shown as a function of force development relative to the maximum isometric value. Symbols in Fig. $2 B$ represent the same techniques (generally employed by other investigators) as shown in Fig. $2 A$. These results have been derived from twitches of isolated papillary muscles (from cats and rabbits) studied at $18-29^{\circ} \mathrm{C}(\bullet, 31 ; \Delta, 8 ; \circ$, $2 ; \times, 11)$. The dashed line is an isometric line to be discussed later. Certainly $\mathrm{E} \neq \mathrm{I}+\mathrm{W}$, and only rarely if at all does any isotonic contraction liberate more energy than the maximum isometric contraction. These results are strikingly different from Fenn's data and cannot lead to the same conclusions.

What factors are responsible for the variability observed in Figs. 1 and 2? Deviations from Fenn's results are greatest at lightest afterloads. Factors that tend to decrease energy liberation at small afterloads in comparison to the maximum isometric value include: shorter initial length (smaller preload) (14); higher temperature (19); a twitch instead of a tetanus (10); lower twitch-totetanus ratio (10); increased compliance of muscle and 
connections; nonparallel fibered preparations (26); fatigue (4); and deactivation of muscle at short lengths (36). To duplicate Fenn's results one must study twitches or brief tetanic contractions in frog sartorius muscle at low temperatures. Further it seems that in Fenn's studies the muscles were initially stretched beyond the length where isometric force was maximum. Contraction from this longer initial length also contributed to the observed results $(10,14)$. Thus it appears serendipitous, but not completely so, that Fenn picked the optimum conditions to defeat the viscoelastic theory of contraction. Any other muscle, or even the sartorius, under any other conditions probably would have produced equivocal results. The list of factors contributing to the variability of these experiments explains why data from cardiac muscle could fall below skeletal muscle results. Cardiac muscle has been studied almost exclusively at high temperatures, at short initial lengths, under conditions where length deactivation would be considerable (21), in twitches, and with preparations possessing a large compliance due to damage (9). Thus it is not proven that cardiac muscle is intrinsically different from skeletal muscle in the Fenn effect.

\section{UNIFYING CONCEPT}

Is there a unifying concept that can be identified amongst the diversity of results so far examined? Important clues were elucidated by Hill (14) and Fischer (7). Hill (14) showed that it was possible to reproduce the variability similar to that shown in Fig. $2 A$ by altering the initial muscle length at which afterloaded contractions were induced. Shorter initial muscle lengths led to results similar to the minimum values of Fig. $2 A$, and longer initial lengths led to results similar to the highest values of Fig. $2 A$. According to Hill (14), “...there are two factors involved: (a) an increase of total energy with work done and (b) a dependence of energy liberation on muscle length." Employing oxygen consumption measurements, Fischer (7) (• of Fig. 2A) reached similar conclusions. The issue was concisely stated, but as Woledge (40) emphasizes, "Incredibly the results of these studies were largely forgotton." Fenn (6) also stated that "...the work is so little with the small loads that the excess heat due to work is easily overshadowed by the decrement due to the diminution in length. We might express the matter better by saying that work involves a liberation of heat in excess of the equivalent isometric heat." Fenn went on to suggest that the equivalent isometric heat or energy be taken as the energy liberated in an isometric contraction at the various lengths concerned. Thus the maximum isometric energy liberation is not the appropriate base line with which to compare energy liberation in working contractions. To unmask the effect of work on energy cost one must minimize effects of length per se on energy liberation or compensate for length effects by considering an equivalent isometric energy base line. Mommaerts and colleagues $(13,19,27-29)$ have investigated these problems. The concept that evolved suggested that the equivalent isometric-energy base line should not be an equivalent length but rather an equivalent force base line. Thus energy liberation during an isotonic contraction should be compared to energy lib- eration during an isometric contraction where the muscle developed a force equivalent to that of the isotonic contraction. This comparison presumes that the energyyielding processes leading to force production occur to the same extent if an equivalent force is developed at a constant length or during shortening. The most appropriate estimate of the equivalent force base line was thought to be derived from stretched muscle preparations where isometric force was varied by changing muscle length on the descending limb of the length-tension relation $(19,20,35)$. An example (19) of the utility of this approach is shown in Fig. 3 where experiments similar to those of Figs. 1 and 2 were conducted on frog muscles at $0^{\circ} \mathrm{C}$ (Fig. $3 A$ ) and $20^{\circ} \mathrm{C}$ (Fig. $3 B$ ). Energy liberation relative to the maximum isometric value was measured in twitches as a function of isotonic or isometric force production relative to the maximum isometric value. Work done during the isotonic contraction also is shown. Results at $0^{\circ} \mathrm{C}$ are reminiscent of those of Fenn (Fig. $1 A$ ), i.e., $\mathrm{E} \cong \mathrm{I}+\mathrm{W}$. On the contrary, when muscle temperature is raised to $20^{\circ} \mathrm{C}$, isotonic energy liberation is drastically reduced. Clearly these results do not resemble Fenn's. What caused this dramatic shift? Note that work done in the twitch decreased when muscle temperature was increased from 0 to $20^{\circ} \mathrm{C}$. This occurs apparently because the temperature sensitivity of reactions leading to force and work production is less than the temperature sensitivity of reactions leading to relaxation (19). Does work lead to an extra production of energy? In this experiment the answer seems to depend on muscle temperature. But Mommaerts and colleagues (19) suggest that work leads to extra energy liberation in both cases once an equivalent force base line is considered. The equivalent force base line as shown in Fig. 3 is the isometric energy liberation determined from stretched muscles. [The nonzero intercept of the isometric energy vs. force relation in Fig. 3, $A$ and $B$ is thought to represent the energetic reactions associated with the cyclic movements of activator $\mathrm{Ca}^{2+}$ during muscle contraction (20, $32,35)$.] In both cases $\left(0\right.$ and $\left.20^{\circ} \mathrm{C}\right)$ energy is liberated above the equivalent force base line in isotonic contractions under all afterloads. Further, more energy is liberated than can be attributed to work done alone. This extra energy may be related to the waste heat that accompanies work production that is not $100 \%$ mechanically efficient. The same logic has been applied to cardiac muscle $(2,13)$. Figure $2 B$ shows, as a dashed line, the equivalent isometric energy liberation, i.e., isometric energy liberation as force is altered by changing muscle length on the ascending limb of the length-tension diagram. (Cardiac muscle cannot be reproducibly stretched to the descending limb of the length-tension diagram.) Employing this base line as a reference, cardiac muscle doing external work liberates more energy than the equivalent isometric contraction. Mommaerts (28) has summarized this equivalent force approach in the following way: " 'a muscle doing work mobilizes, over and above that needed for activation and the maintenance of tension, energy accounting for the work and for the dissipation of energy accompanying the work process." "

Three retrospective points should be mentioned. First, because Fenn observed that $\mathrm{E} \cong \mathrm{I}+\mathrm{W}$, the impression 
A

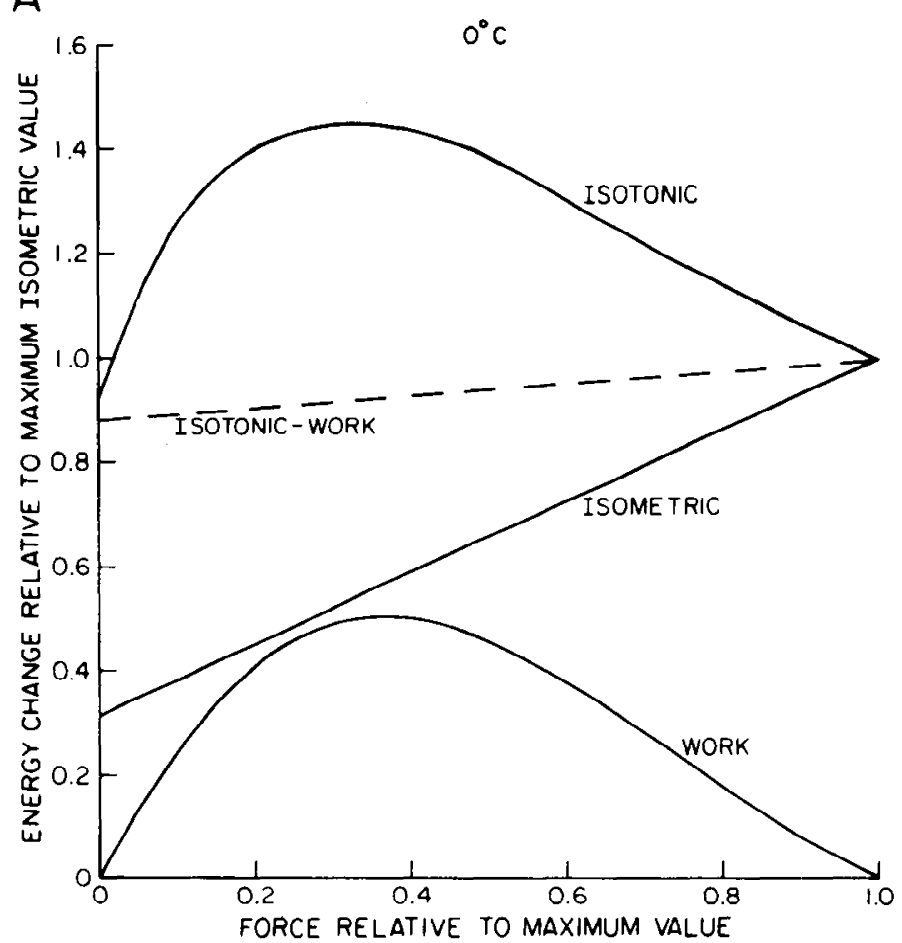

FIG. 3. Energy cost at $0^{\circ} \mathrm{C}(A)$ and $20^{\circ} \mathrm{C}(B)$ as a function of afterload in isotonic twitches (isotonic) and as a function of force in isometric twitches at stretched lengths (isometric). Results plotted as multiples of maximum isometric values. External work performed in isotonic twitches (work) also shown. Dashed line labeled isotonic-work

was held by some that this implied that work was done at $100 \%$ mechanical efficiency. But it has been pointed out (27) that it would not be possible for $100 \%$ efficiency to occur over widely differing shortening velocities. Also it should be added that Fenn never suggested that work was done at $100 \%$ efficiency (6): "This does not mean, of course, that the work is accomplished with 100 percent efficiency, but rather that extra energy must be mobilized in proportion to the work done. All of the energy may have been necessary, in one way or another, for the performance of the work." The second point concerns the use of the maximum isometric energy liberation as the base line to which results of all other contractions are compared. It is clear that this approach was a remnant of the viscoelastic theory of contraction. With the demise of this theory there seems to be little justification for comparing energetics of working contractions to the maximum isometric contraction. The third point relates to the Fenn effect as conceived from the viewpoint of rates of energy liberation. It might be stated that increased work production leads to an increased rate of energy liberation $(3,15)$. There are complications with this approach: only myothermic techniques can readily measure rates of energy cost during contraction; energy liberated from moment to moment during muscle shortening cannot be attributed simply to phosphocreatine or ATP hydrolysis (33); and cardiac muscle does not exhibit an increase in the rate of energy liberation during shortening (9). Thus it is not clear whether further insight can be gained from this approach at the present time. Nonetheless the view that increased work production leads to an increased rate of energy liberation is not

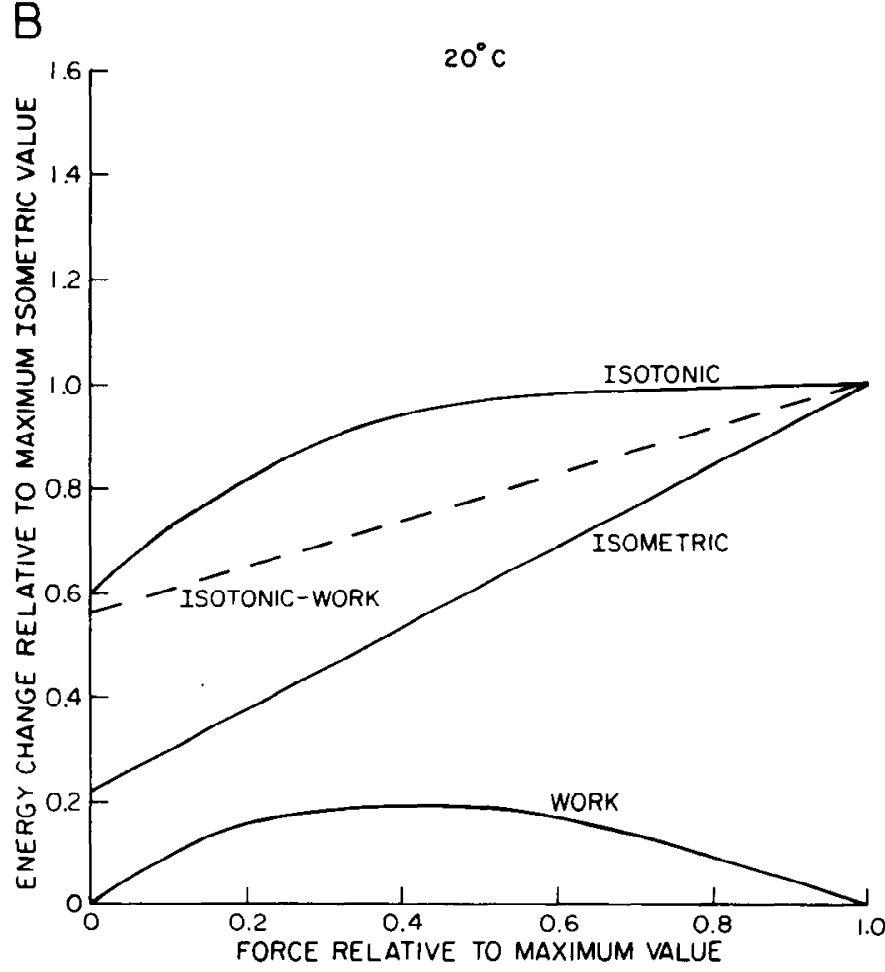

represents the energy liberation remaining after work is subtracted from the isotonic energy liberation. This line is a best-fit relation drawn through the actual data. In principle, isotonic and isotonic-work curves should intersect at 0 load. The fact that they do not reflects variability in the actual data. Data from Homsher et al. (19).

inconsistent with the approach suggested by Mommaerts and colleagues $(19,27)$.

\section{CONCLUSIONS}

The following points should be emphasized. 1) It seems debatable that any redefinition of the concept of the Fenn effect will lead to greater clarification. One cannot change Fenn's results or conclusions. 2) Therefore, the Fenn effect should be considered as $E \cong I+W$, and it should further be recognized that this relation is not generally valid and is thus of limited utility. 3) The approach developed by Mommaerts $(27,28)$ to compare energy liberated in working contractions to isometric contractions generating an equivalent force is a useful and unifying concept. Nonetheless this approach suffers, as do all phenomenological views, in that in and of itself it provides little insight into molecular mechanisms (9). 4) Fenn's experiments on muscle energetics have been and will continue to be remembered as a triumph over a theory of muscle contraction that existed in one form or another for three-quarters of a century. 5) Finally, Fenn's results were the first to demonstrate beyond doubt that muscle possesses a fundamental property that enables it to adjust its energy cost to prevailing mechanical constraints after stimulation. Nearly one-half of a century later this property, permanently linked to Fenn's name, still seeks a satisfactory molecular elucidation.

The author is most grateful to E. Bozler, B. A. Schottelius, and R. C. Woledge for thoughtful criticism of this manuscript.

J. A. Rall is a recipient of Research Career Development Award 1K04NS-00324 from the National Institutes of Health. 


\section{RFFERENCES}

1. Carlson, F. D., D. J. Hardy, and D. R. Wilkie. Total energy production and phosphocreatine hydrolysis in the isotonic twitch. J. Gen. Physiol. 46: 851-882, 1963.

2. Coleman, H. N., E. H. Sonnenblick, and E. Braunwald. Myocardial oxygen consumption associated with external work: the Fenn effect. Am. J. Physiol. 217: 291-296, 1969.

3. Curtin, N. A., AND R. C. Woledge. Fnergy changes and muscular contraction. Physiol. Rev. 58: 690-761, 1978.

4. Fenn, W. O. A quantitative comparison between the energy liberated and the work performed by the isolated sartorius muscle of the frog. J. Physiol. London 58: 175-203, 1923.

5. FENN, W. O. The relation between the work performed and the energy liberated in muscular contraction. J. Physiol. London 58: 373-395, 1924.

6. Fenn, W. O. Isotonic contractions in muscle. Cold Spring Harbor Symp. Quant. Biol. 4: 233-241, 1936.

7. Fischer, E. The oxygen-consumption of isolated muscles for isotonic and isometric twitches. Am. J. Physiol. 96: 78-88, 1931.

8. Gibbs, C. L. Cardiac energetics. In: The Mammalian Myocardium, edited by G. A. Langer and A. J. Brady. New York: Wiley, 1974, p. $105-133$

9. Gibbs, C. L. Cardiac energetics. Physiol. Rev. 58: 174-254, 1978.

10. GibBs, C. L., AND J. B. Chapman. Effects of stimulus conditions, temperature, and length on energy output of frog and toad sartorius. Am. J. Physiol. 227: 964-971, 1974.

11. Gibbs, C. L., and W. R. Gibson. Energy production in cardiac isotonic contractions. J. Gen. Physiol. 56: 732-750, 1970.

12. GibBs, C. L., AND W. R. Gibson. Energy production of rat soleus muscle. Am. J. Physiol. 223: 864-871, 1972.

13. Gibbs, C. L., W. F. H. M. Mommaerts, and N. V. Ricchiuti. Energetics of cardiac contractions. J. Physiol. London 191: 25-46, 1967.

14. Hill, A. V. The heat production in isometric and isotonic twitches. Proc. Roy. Soc. Lond. Ser. B 107: 115-131, 1930.

15. Hill, A. V. The heat of shortening and the dynamic constants of muscle. Proc. Roy. Soc. Lond. Ser. B 126: 136-195, 1938.

16. Hill, A. V. Trails and Trials in Physiology. London: Arnold, 1965.

17. Hill, A. V. First and Last Experiments in Muscle Mechanics. Cambridge, UK: Cambridge Univ. Press, 1970.

18. Hill, A. V., AND R. C. Woledge. An examination of absolute values in myothermic measurements. J. Physiol. London 162: 311$333,1962$.

19. Homsher, E., W. F. H. M. Mommaerts, and N. V. Ricchiuti. Energetics of shortening muscles in twitches and tetanic contractions. II. Force-determined shortening heat. J. Gen. Physiol. 62: 677-692, 1973.

20. Homsher, E., W. F. H. M. Mommaerts, N. V. Ricchiuti, and A. WALLNER. Activation heat, activation metabolism and tensionrelated heat in frog semitendinosus muscles. J. Physiol. London
220: $601-625,1972$.

21. JEWELL, B. R. A reexamination of the influence of muscle length on myocardial performance. Circ. Res. 40: 221-230, 1977.

22. Jöвsis, F. F. Energy utilization and oxidative recovery metabolism in skeletal muscle. Curr. Top. Bioenerg. 3: 279-349, 1969.

23. JöBsis, F. F., AND J. C. DufFifi.d. Force, shortening, and work in muscular contraction-relative contributions to overall energy utilization. Science 156: 1388-1392, 1967.

24. Katz, B. Archibald Vivian Hill. Biogr. Mem. Fellows R. Soc. 24: $71-149,1978$.

25. Levin, A., AND J. Wyman. The viscous elastic properties of muscle. Proc. Roy. Soc. Lond. Ser. B 101: 218-243, 1927.

26. Martin, D. S. The relation between work performed and heat liberated by the isolated gastrocnemius, semitendinosus and tibialis anticus muscles of the frog. Am. J. Physiol. 83: 543-547, 1928.

27. Mommaerts, W. F. H. M. Energetics of muscular contraction. Physiol. Rev. 49: 427-508, 1969.

28. Mommaerts, W. F. H. M. What is the Fenn-effect? Naturuissenschaft 57: 326-330, 1970.

29. Mommaerts, W. F. H. M., I. Seraydarian, and G. Marechal. Work and chemical change in isotonic muscular contractions. Biochim. Biophys. Acta 57: 1-12, 1962.

30. Needham, D. M. Machina Carnis. Cambridge, UK: Cambridge Univ. Press, 1971.

31. Poul, P. E., B. M. Chandlek, S. C. Seagren, and H. E. SonnenBLICK. Mechanochemistry of cardiac muscle. II. The isotonic contraction. Circ. Res. 22: 465-472, 1968.

32. RALL, J. A. Energetics of $\mathrm{Ca}^{2+}$ cycling during skeletal muscle contraction. Federation Proc. In press.

33. Rall, J. A., E. Homsher, A. Wallner, and W. F. II. M. MomMAERTS. A temporal dissociation of energy liberation and high energy phosphate splitting during shortening in frog skeletal muscles. J. Gen. Physiol. 68: 13-27, 1976.

34. Rai.I, J. A., AND B. A. SChOtTflius. Energetics of contraction in phasic and tonic skeletal muscles of the chicken. J. Gen. Physiol. 62: 303-323, 1973.

35. Sмiтн, I. C. H. Energetics of activation in frog and toad muscle. $J$. Physiol. London 220: 583-599, 1972.

36. TAYloR, S. R., AND R. Rudel. Striated muscle fibers: inactivation of contraction induced by shortening. Science 167: 882-884, 1970.

37. WENDT, I. R., AND C. L. GiBBs. Energy production of rat extensor digitorum longus muscle. Am. J. Physiol. 224: 1081-1086, 1973.

38. WhaleN, W. J. The relation of work and oxygen consumption in isolated strips of cat and rat myocardium. J. Physiol. London 157: $1-17,1961$.

39. White, D. C. S., And J. Thorson. The kinetics of muscle contraction. Prog. Biophys. Mol. Biol. 27: 175-255, 1973.

40. Woledge, R. C. Heat production and chemical change in muscle. Prog. Biophys. Mol. Biol. 22: 37-74, 1971. 